\title{
When does electricity price cap regulation become distortionary?
}

\author{
Paul Simshauser * \\ Level 6, 144 Edward Street \\ Brisbane, QLD 4001. \\ Email: psimshauser@agl.com.au \\ Tel: +61 299212375 Fax: +61299212424
}

\begin{abstract}
Australia has a deregulated national wholesale electricity market, a national network regulatory framework, but inconsistent State-based regulated retail price caps in workably competitive markets. This article finds that asymmetric information and the complexity of energy markets means that a regulator, no matter how wise and well resourced, could ever be expected to produce reliable estimates of competitive prices. If regulation represents a policy constraint, relying on long-run concepts rather than shortrun prices is least damaging to the flow of capital and non-linear pricing.
\end{abstract}

Keywords: Electricity Prices, Price Regulation, Energy Policy.

JEL Codes: D24, L11 and Q48.

\section{Introduction}

Australia has a fully deregulated wholesale electricity market which spans Queensland, New South Wales, Victoria, South Australia, Tasmania and the Australian Capital Territory, and represents the world's largest fully synchronised power system in geographical terms. Australia also has a national approach to setting electricity network prices. Ironically however, the highly competitive retail market faces State-based 'regulated price caps' in four of the six regions. ${ }^{1}$ Each region also adopts a different approach to setting regulated price caps. Regulatory outcomes are not always predictable and most recently the methodology in Queensland changed materially, from using long run costs to short run prices when setting the wholesale component of the price cap. ${ }^{2}$ This was in direct response to transient structural oversupply, and seemingly a belief that using long run marginal cost results in 'sticky customers' paying too much for their electricity services and produces excess profits to energy firms.

Policymaking in electricity is rarely clear cut. First, energy firms do not rely exclusively on short run instruments when committing to wholesale transactions. On the contrary, no new generating capacity can be built on the basis of short run transactions - bank finance requires long term commitments from credible counterparties. While this might be prima facie considered an irrelevant proposition during an episode of structural oversupply, a dynamic inconsistency problem is more than a theoretical possibility. Second, electricity tariffs are subject to considerable non-linearity, and truncating retail tariffs at one end will result in non-trivial price rises at the other end. Evidence from other energy-only markets demonstrates that constraining non-linear prices damages competition and raises prices at the margins.

The mix of a deregulated national wholesale market, national network regulatory framework and inconsistent State-based retail price regulation is a somewhat unique problem in the literature on energy markets, and is thus worthy of investigation. A recent review of electricity price regulation in Australia by the Productivity Commission (2013) concluded, perhaps

\footnotetext{
- Paul Simshauser is the Chief Economist at AGL Energy Ltd and Professor of Economics at Griffith University. AGL Energy Ltd serves 3.5 million electricity and gas customers in the National Electricity Market. Any errors remain the responsibility of the author. ${ }_{1}^{1}$ Victoria and South Australia removed price cap regulation in 2008 and 2013, respectively.

${ }^{2}$ Historically in Queensland, an LRMC-equivalent price cap was escalated by the indexed movement of plant entry costs and short run prices using a 50/50 weighting. The result was nonetheless broadly consistent with long run marginal costs.
} 
unsurprisingly, that State-based retail price controls should be removed in regions where workable competition exists and also forms a part of Banks' (2012) productivity 'To Do' list. That artificial retail price caps remain in workably competitive regions remains one of the enduring mysteries of stalled National Electricity Market (NEM) reforms. No clear public policy objective has ever been articulated for its protracted use.

That said, the purpose of this article is not to analyse the efficacy of retail price cap regulation. Instead, price cap regulation is assumed to be a binding policy constraint imposed by individual jurisdictions due to the political economy of residential electricity tariffs. The purpose of the present article is to analyse how best to implement that constraint in a workably competitive market and do 'least damage' to its proper functioning. This article is structured as follows: Section 2 examines the structure of electricity tariffs. Section 3 explains the case for using short run market prices. Section 4 reviews the use of long run marginal cost. Policy implications and concluding remarks follow.

\section{The cost and structure of residential electricity tariffs}

Consumers in Australia's National Electricity Market (NEM) are supplied by electricity retailers who effectively bundle the cost streams associated with generation, transmission, distribution, environmental charges, retail marketing and retail billing costs into a final end-use tariff. Of these, generation costs are characterised by considerable uncertainty - NEM wholesale prices are among the most volatile of any commodity or security market in the world with annual averages ranging from $\$ 25$ - $\$ 73 / \mathrm{MWh}$ over the past decade. Wholesale prices are formed in an energyonly, uniform first-price auction clearing mechanism where ever more volatile half-hourly clearing prices range from $-\$ 1000$ to $+\$ 13,100 / \mathrm{MWh}^{3}{ }^{3}$ This volatility makes it an especially risky market for buy- and sell-side wholesale participants.

Generators and retailers hedge their spot price risks by using a variety of instruments from quarterly swaps, options, and futures contracts to very long dated Power Purchase Agreements some spanning 25 years-to-maturity. For retailers, entering into forward contracts of varying tenors in an attempt to mitigate price risk is imperfect given differences between highly weathersensitive customer loads and the bounded rationality of forward contracts. As a result, and due to corporate financing constraints now facing merchant generators, the three largest (incumbent) retailers have partially re-integrated by developing or acquiring generation plant in order to establish substantially less bounded physical hedges, with that trend accelerating from about 2002 onwards. ${ }^{4}$ To be clear, most retailers remain 'short' - meaning that they still rely on financial instruments to hedge their overall load - and the practical evidence tends to suggest this is a desirable portfolio state.

In between electricity wholesalers and retailers are the transmission and distribution networks, which are regulated monopolies facing five-year price paths set by the Australian Energy Regulator according to a regulated rate of return. ${ }^{5}$ Network tariffs are generally passed through to electricity consumers by retailers since the cost is common to all rivals.

Although there are six NEM regions, there are nominally 13 distribution network 'patches' and in each patch one retailer is notionally classed as 'the incumbent'. In Western Sydney for example, Endeavour Energy owns the network assets and Origin Energy is the incumbent retailer. The

\footnotetext{
${ }^{3}$ The Australian Energy Market Operator has extensive materials on its website that explain how the wholesale market functions. See www.aemo.com.au for further details.

${ }^{4}$ Nelson and Simshauser (2013) explain that from c.2004, new power plants required a long-dated Power Purchase Agreement, written by a counterparty with an investment grade credit rating (i.e. BBB- or better), in order to secure the appropriate debt commitments from lenders.

${ }^{5}$ Regulated rates of return are set according to the approved asset base and the Weighted Average Cost of Capital, with cost of equity estimates based on the Capital Asset Pricing Model developed by Sharpe (1964) and Lintner (1965).
} 
roughly 10 rival retailers are therefore entrants to that patch, and are known as 'second-tier' retailers in that particular patch.

Default tariffs exist in all regions and are offered by all retailers in one form or another. This includes the Victorian and South Australian regions, where price cap regulation has been removed. So how do incumbent retailers set default tariffs in fully deregulated markets where no regulated 'focal point' exists? In deregulated retail markets such as Victoria and South Australia, New Zealand, Great Britain, Norway, Sweden, Netherlands, Germany, Italy, Austria and Texas, default tariffs are typically set in a manner that is broadly consistent with industry long run marginal costs. Default Tariffs can be expected to rise above long run marginal cost under system stress conditions but conversely, default tariffs tend not to fall below long run cost during periods of structural oversupply because they are a 'default offer' for energy services. This latter point warrants further discussion.

Because a basic amount of electricity is considered an essential service ${ }^{6}$, a unique characteristic of default tariffs is that they must be made available to all consumers by the incumbent retailer in each patch as a (government-imposed) condition of retaining their business licence. These default tariffs are made available to all in-area customers without knowledge of consumption levels, intended loyalty, transaction costs from subsequent switching, or credit quality and risk of non-payment. A small but non-trivial number of electricity customers are in practice loss-making but such customers still have a right to access the default tariff. The default product must therefore account for considerable information asymmetries.

Default tariffs also perform an important function in competitive markets because they represent the 'price-to-beat' by second-tier entrants. In contrast, competitive or 'market contracts' are offered by both incumbent and second-tier retailers. While each non-incumbent's reference (or standing) market contract may differ little from the incumbents' default tariff, a varied combination of alternative offers exists with discounts increasing according to variables such as contract tenor, dual (gas and electricity) fuel accounts, payment method and so on. Actively marketed contracts typically involve $5-15 \%$ discounts to variable charges in order for second-tier retailers to gain market share, or for incumbents to defend market share. This is essentially an example of $2^{\text {nd }}$ and $3^{\text {rd }}$ degree price discrimination via tariff schedules and customer segmentation - although Armstrong (2006) classifies this as behaviour-based price discrimination associated with 'customer poaching'. The magnitude of product discounting amongst retailers generally intensifies when system oversupply and/or retailer margins are perceived to be greatest and at times has reached $25 \%$ during particularly intense episodes of rivalry (i.e. price wars). ${ }^{7}$ The differential between default tariffs and discounted market contracts is therefore a good guide to the intensity of competitive activity (Hviid and Waddams Price, 2012).

For the 2012/13 regulatory determination, the Queensland regulator made a significant shift in its approach to setting the regulated price cap. This change involved setting the generation cost component by reference to short run prices observable from the futures market (and forecast yearahead half-hourly spot prices) rather than the use of long run generation costs. As the market was in a state of structural oversupply, it meant that the generation component of the default tariff dropped substantially (by 1.9c/kWh). As such, the Default Tariff was 'truncated' by regulation rather than market forces. This effect is illustrated in Figure $1 .{ }^{8}$

\footnotetext{
${ }^{6}$ Although as one peer reviewer noted, while electricity is often flagged for special attention given its essential service characteristics, it is no more essential than housing, food and health services. ABS data on household expenditure places energy into context representing $2.6 \%$ of household expenditure by comparison to housing costs (18\%), food (16.5\%) and health services (5.3\%). ${ }^{7}$ Such price wars are typically driven by pressure arising from the equity capital markets, given the tendency of buy- and sell-side stock analysts to focus on the customer numbers of listed entities in their company valuations (i.e. as a short-hand measure of value).

${ }^{8}$ The data in Figure 1 excludes the effect of the additional Queensland Government-imposed 'tariff freeze'.
} 
Figure 1: $\quad$ 2012/13 Tariff Structures in Queensland

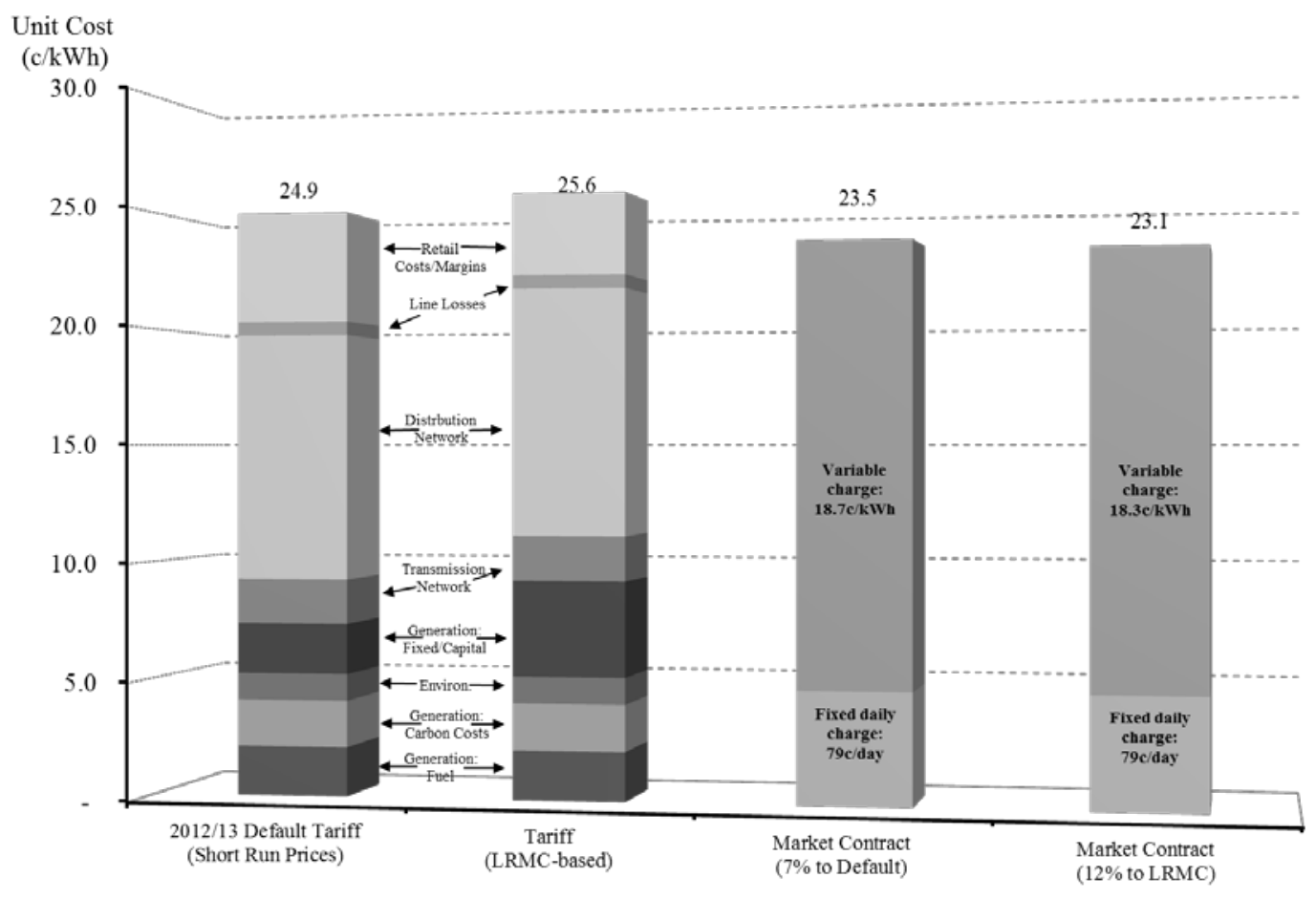

The 2012/13 Default Tariff is illustrated by the first bar in Figure 1 and totals 24.9c/kWh and highlights the discrete cost components. This includes generation fuel (i.e. coal and natural gas), carbon costs, environmental charges (i.e. subsidy costs to utility-scale renewables and rooftop solar PV), the quasi-contribution to generation fixed/capital costs (given estimated short run prices were $1.9 \mathrm{c} / \mathrm{kWh}$ below total cost), regulated transmission and distribution network charges, line losses and retail costs and margins - including an additional 5\% 'headroom' which is designed to ensure competition is not stifled. From a consumer perspective, the Default Tariff is structured as a conventional two-part tariff with a fixed daily charge of 79c/day and a variable charge of $20.1 \mathrm{c} / \mathrm{kWh}$ - which results in an average charge of $24.9 \mathrm{c} / \mathrm{kWh}^{9}$

The second bar illustrates what the 2012/13 Default Tariff would look like using an LRMC approach. There are two primary differences between the first and second bar: (1) the LRMC tariff includes an additional 1.9c/kWh with the generation (fixed/capital) cost component set at normal profit levels based on an optimised plant stock ${ }^{10}$, and (2) there is no 'headroom' included in retail costs and margins, although as Yarrow (2008, p.6) explains, there should be:

Promotion of consumer interests might, therefore, require policies that lead to higher prices today, if the effect is to promote investment and innovation that can be expected to deliver better value for money in the future... It is therefore important to recognise that consumers can be harmed as a result of under-pricing because under-pricing tends to restrict the supply-side of markets, certainly in the longer-term by discouraging investment and innovation...

The final two bars are indicative of competitive 'market contracts' prevailing before, and after, the 'wholesale cost' design change. Notice that the third bar is labelled 'Market Contract - $7 \%$ to Default' meaning that it is a 7\% discounted product to the short-run price-based Default Tariff

\footnotetext{
${ }^{9}$ This is based on average household consumption of 6,000 kWh/a.

${ }^{10}$ By using an optimised plant stock, inefficient fixed and sunk costs associated with structural oversupply are basically eliminated such that total tariff revenues would not be sufficient to cover surplus-to-requirement generator costs.
} 
(i.e. the first bar) and is thus $23.5 \mathrm{c} / \mathrm{kWh}^{11}$ The final bar is set at a $12 \%$ discount to the LRMCbased tariff (i.e. the second bar) and is 23.1c/kWh. Prior to the regulatory change in 2011/12, retailers routinely offered discounts of up to $12 \%$ from the then LRMC-based tariff. ${ }^{12}$ After the change to short run prices, routine discounts contracted to $7 \%$. This leads to an apparent policy dilemma. Is a lower Default Tariff with thin discounts more efficient than a higher Default Tariff set at industry cost with deep discounts widely available?

\section{The use of short run wholesale prices}

Price cap regulation in Queensland is a policy constraint. ${ }^{13}$ The most recent regulatory determination involved shifting the methodology for setting price caps to levels perceived to be efficient by reference to spot and short-tenor forward contract prices, rather than using LRMC as a safety-net. Such an approach reflected the view of the state regulator that the use of LRMC leads to unnecessary premiums for sticky customers.

A principal argument against the use of LRMC in setting default tariffs is that it is unlikely to bear any resemblance to the short run price of energy in the present year as it ignores the allocative and dynamic efficiency of markets - specifically, real-world oversupply and undersupply events, inter-temporal movements in fuel prices and historic contractual positions.

Another claim was that a regulator can simulate the construction of a portfolio of 1, 2 and 3-year hedge contracts with data observable from the futures market, and combine these with half-hourly simulation forecasts of year-ahead spot prices to represent the actions of a 'prudent retailer' in an energy market. By contrast, the use of LRMC in setting Default Tariffs excludes the effects of contracting.

While LRMC calculations are generally acknowledged as being a reasonable reflection of the annualized costs associated with investment in power plant, in a deregulated market, it was argued that generation investment decisions are in the hands of investors and accordingly, losses incurred or rents accrued from short run markets should remain with those investors.

As a result, the regulatory determination in Queensland used short-run hedge instruments of 1-3 years in tenor. All hedging instruments beyond three years, and in particular, Power Purchase Agreements (PPAs) which generally span 15-25 years, were excluded (nb. PPAs are invariably struck at a contemporaneous LRMC value and escalated annually thereafter). ${ }^{14}$ Direct investments in generation by integrated generator/retailers, which are essentially synthetic or internalised PPAs, were also excluded. This was an important decision because the volume of PPAs and synthetic PPAs in the NEM are non-trivial in every respect, given such instruments are now a pre-condition for entry as Nelson and Simshauser (2013) explain. The reasoning for excluding PPAs is that they were not considered representative of efficient contractual arrangements on an intra-business cycle basis. It was argued that PPAs are designed to provide stable returns to asset owners and in theory should cost no more than the accumulation of spot market and short-dated contract purchases across the energy market business cycle. And so intracycle gains and losses arising from PPAs should be 'marked' against the short-run market.

\footnotetext{
${ }^{11}$ Note that the $7 \%$ discount is only applied to the variable charge.

${ }^{12}$ On-line offers (and intervention/matching by incumbent retailers) are typically at deeper discounts given the lower acquisition cost.

${ }^{13}$ After this manuscript was drafted in mid-2013, the Queensland State Government announced in that it will remove regulated price caps from 1 July 2015.

${ }^{14}$ PPAs are the primary instrument used to facilitate new plant entry, and are inevitably struck at the long run costs of a given technology for banking purposes. As Nelson and Simshauser (2013) explain, PPAs are quite fundamental to the reliable flow of supply-side investments in the NEM. PPA's can be traced back to the early 1980s, and were first associated with thermal plant. They are usually very long-dated agreements that contain a fixed price which escalates annually, to purchase most or all of the power from a given power station. PPAs for thermal plant usually comprise two revenue streams (1) fixed monthly payments which occur regardless of output, and (2) variable monthly payments based on output and the fuel consumed in the process of production. So the fixed payments typically include funds adequate to pay for labour, non-fuel materials, scheduled debt repayments, taxation costs and a normal return on equity capital to owners. PPAs typically have performance requirements, e.g. plant availability targets or production targets and if not met, financial penalties apply.
} 
A key issue arising from excluding LRMC calculations from the determination of Default Tariffs is whether Resource Adequacy would be affected over the long run, that is, whether requisite future generation investments would be delayed or stifled. The Queensland regulator acknowledged that incorporating LRMC as applied in other NEM regions may provide additional security for future investment in generation but considered that such a requirement is not necessary given current market conditions (i.e. oversupply). Above all, the case for short run pricing essentially relies on the notion that generation and retail businesses are 'strictly separate' and that PPAs are not efficient contracts.

\section{The use of LRMC in setting price caps}

The starting premise for the use of LRMC is that the case for regulated price caps in workably competitive markets is weak to begin with. But to the extent that it represents a policy constraint, regulated price caps should form a 'safety-net' and allow the competitive market to deliver the competitive price and quality of energy services, rather than have a regulator attempt to define an efficient clearing price. Caution is necessary before prima facie concluding that the use of LRMC impounds unnecessary premiums. LRMC calculations usually involve a Greenfields approach to power system modelling in which aggregate electricity demand is assumed to be met by a fleet of state-of-the-art new entrant plant, calibrated to ensure the optimal mix of base, semibase and peaking plant is deployed, thereby utilizing the rich blend of fixed and variable costs to minimize the overall cost of supply. Additionally, 'tolerable blackouts' are optimised to avoid inefficient costs associated with over-equipment. ${ }^{15}$ Rarely will a power system resemble this 'ideal state' in practice given sunk plant, disaggregated and uncoordinated investment decisionmaking and investment commitments under conditions of considerable uncertainty.

Greenfield LRMC calculations are forward looking and ignore sunk investment decisions. Using this approach, regulated price caps would be adequate to ensure that new plant of the appropriate technology, capital structure and resource cost could enter and meet the expected returns of the marginal capital deployed if new plant was required. To be clear, an LRMC calculation assumes there is neither oversupply nor undersupply - in this sense it is highly optimised and one implication of this is that in an oversupplied market, an LRMC result will virtually ensure economic losses are incurred by an incumbent retailer due to product discounting by rivals. There is, therefore, no incentive to over-capitalise the system through over-investment.

A short-run linear price approach has a non-trivial risk of distorting the competitive market and suppressing prices because regulators rely on highly imperfect information and, by defining as efficient only futures contracts with tenors spanning 1-3 years, incorrectly specifies the efficiency benchmark given financing constraints and substantial fixed and sunk costs associated with wholesale supply.

The assumptions underlying the use of short run pricing collides with financial economic and microeconomic principles in three primary areas; (1) industrial organisation and in particular, that generation and retail business models can no longer be treated as 'strictly separate' if a long-run efficient market is to prevail due to capital market constraints; (2) asymmetric information and the inability of regulators to accurately set an efficient price without risk of damaging competition and inducing wealth transfers through error, and (3) the adverse welfare implications of truncating non-linear pricing in an industry with substantial fixed and sunk costs.

\footnotetext{
${ }^{15}$ To be clear, no power system in the world has been built to eliminate blackouts - the cost of doing so is prohibitive. Reliability standards represent a policy choice. In the NEM, the reliability criteria has been defined as 'no more than $0.002 \%$ unserved energy per annum'. This standard was set by the NEM's 'Reliability Panel' in 1998 and is intended to represent the point at which the marginal cost of supply equals aggregate consumers' marginal willingness to pay. From this standard, the market price cap can then be derived in a manner designed to ensure adequate price signals exist for the entry of 'peaking plant' once unserved energy approaches the reliability limit. For further details on the NEM’s reliability standard, see Roam (2010).
} 


\subsection{Industrial organisation, vertical integration and the broken merchant model}

Should electricity retailers be price cap regulated in isolation as pure-play businesses, or should regulatory strategy aim to contemplate vertically integrated businesses as well? This is an important line of questioning. If the answer is pure-play retail businesses only, then the matter of how the wholesale component of regulated price caps are set could perhaps be argued to be based on short run instruments only. However, this would have profound and adverse effects on the flow of debt and equity capital into fixed capital formation on the supply-side in energy-only markets around the world. As a result, a very different answer emerges:

Principle \#1: In workably competitive energy-only markets, some minimum level of vertical integration of merchant businesses is essential for physical and systemic power system stability.

When energy-only markets were first established, generators and retailers were structurally separated and based on a 'merchant model'. As Finon (2008) explains, the canonical supply-side business model in deregulated energy markets was the Merchant Power Producer, a stand-alone generator that sold its production to the spot and short-term forward markets (i.e. without longterm PPAs), underpinned by non-recourse project finance. In this ideal world, the counterparties to Merchant Power Producers were expected to be stand-alone Retailers that buy all their requirements from spot and short term forward markets. In this instance the use of 1-3 year hedge contract prices to set default tariffs might be a reasonable approach. But by the mid-2000s, widespread financial distress and bankruptcies of merchant plant in energy-only markets around the world changed the market for power project finance. From this point, merchant plant relying on 2-3 year hedge contracts for entry became completely un-bankable - something Finon (2008) has described as market failure. This in turn sprouted an entire field of literature in energy economics on 'Resource Adequacy' (see for example Oren, 2003; Joskow and Tirole 2004; Cramton and Stoft, 2006; Joskow, 2006; De Vries 2007; Simshauser, 2008; Finon, 2008; Caplan, 2012; Nelson and Simshauser, 2013). As Finon (2008, p160, p152) observed:

The assumption that a rapid and adequate development of markets for forward contracts and financial instruments will offer the means for hedging risks of new generators has been annihilated after the experience of the first decade of market reform... The record of investments in generation capacity after market liberalisation of the electric industries in the United States and in Europe shows that the institutional conditions of successful capacity development in [power station] equipment are long term contracts and vertically integrated company [sic]...

The analysis in Simshauser (2010) finds identical results for Australia. In short, new plant in energy-only markets like the NEM requires long-dated PPAs or facilitation by a vertically integrated company in order to obtain finance. These are binding constraints imposed by global capital markets (Finon, 2008; Caplan, 2012; Nelson and Simshauser, 2013). And in a further disruption to the original merchant model, the PPA must be written by an entity with an investment-grade credit rating (i.e. BBB- or better), something which stand-alone retailers are evidently incapable of obtaining, let alone maintaining (Simshauser 2010). ${ }^{16}$

An Australian Federal Government inquiry into the NEM concluded that industrial organisation (i.e. vertical integration) would ensure Resource Adequacy in Australia's energy-only market (ERIG, 2006). It seems difficult for a regulator to justify a methodology based on a 'pure play retailer' when it is diametrically opposed to the inquiry findings, and the wealth of academic literature and practical evidence on energy-only markets. Of course, none of this suggests that stand-alone retailers or merchant power producers do not have a role to play in the competitive

${ }^{16}$ The exception to this in Australia has been Government Owned Retailers, who by virtue of their ownership structure, have been able to obtain an investment grade credit rating. 
market. However, their participation in energy-only markets relates primarily to competition and product innovation objectives - they are not, by the literature's definition and findings, capable of making marginal contributions to power system stability.

The evidence in Australia is that incumbent retailers progressively reorganized themselves into (investment grade) credit-rated, vertically integrated, merchant utilities spanning generation and retail, with generation typically being c.40-70\% of peak retail demand. The generating portfolios of vertical entities are in all cases a mix of their own direct investments (i.e. synthetic PPAs between generation and retail divisions) and PPA-sponsored power projects owned by Independent Power Producers.

While facilitating investment in new plant is clearly important, there are other economic incentives for the use of instruments other than short term futures contracts. For a large incumbent retailer whose demand for hedge contracts is non-trivial relative to aggregate demand, constructing a balanced hedge portfolio comprising physical and financial instruments of varying tenors beyond three years is designed to reduce recontracting price and volume execution risk, particularly during periods of power system stress as Gray (2012) explains. Sovereign governments issue bonds of varying tenors beyond three years for the same reason - to reduce refinancing risks. ${ }^{17}$ In the case of energy-only markets, over the long run this contracting activity diminishes the potential for acute wholesale market price shocks (Bushnell, Mansur and Saravia, 2007; Simshauser, 2010). In summary then, a prudent retailer's hedge book cannot be defined as a portfolio duration of approximately two years when all new entrant plant requires PPAs with tenors of no less than 15 years, and when portfolio risks are materially heightened with short-only instruments.

None of this should be interpreted to mean that PPAs should be protected by price regulation and free of economic loss during episodes of structural oversupply. To be perfectly clear on this, even with price caps set at LRMC or some margin above it, the evidence from publicly listed utilities is that in a structurally oversupplied market, ever expanding price discounts will squeeze revenues and the firms will incur economic losses. But, in competitive markets, such losses are usually delivered to participants by the hands of market forces rather than by a regulator acting with imperfect information.

The switch from an LRMC methodology to the use of short run prices during an episode of oversupply, as occurred in Queensland, is likely to be pro-cyclical and aggravate market volatility. ${ }^{18}$ The issue here is the 'dynamic inconsistency problem' - a field of economic research that focuses on the response by firms to policy volatility and the lack of capital markets confidence that ensues.

Generation plant is characterized by scale economies so adding of large blocks of capacity will lower prices in the immediate post-entry environment, an observation that dates back at least as far as Bain (1956), Sylos (1957) and Modigliani (1958) and has been demonstrated in the NEM context in Simshauser (2001) and (2006). The regulatory incentive under a short run approach is that incumbent firms will delay investment or writing PPAs to minimize portfolio losses in the post-entry environment, as Kydland and Prescott (1977) explained in the case of energy and Brito et al. (2011) explained in the case of telecommunications. In addition, the dynamic inconsistency of the policy in the Queensland instance adds a further reason for delay - if policymakers switch

\footnotetext{
${ }^{17}$ Industrial firms, banks and governments raise debt using a variety of instruments, facilities and tenors. In contango markets, shortdated debt instruments are demonstrably cheaper than long-dated debt instruments. Yet industrial firms and governments actively issue (more expensive) longer-dated debt in order to reduce interest rate and refinancing execution risks in future years.

${ }^{18}$ The use of short run pricing in setting regulated price caps may render long-dated PPAs sub-economic during structural oversupply through a regulatory-induced mark-to-market process. As such PPAs would be dis-incentivised in practice. All things being equal, consumers may pay more for their energy in cyclical downturns when PPAs are present, but conversely, delay of new PPAs, or worse, their absence, would have an impressing effect during cyclical upswings because the entry of plant would be constrained.
} 
to short run prices during oversupply, they are capable of switching back to LRMC pricing during an episode of undersupply. In capital-intensive industries, few factors could be more damaging to achieving efficient outcomes than a dynamic inconsistency problem. When perceptions of 'policy uncertainty' become enshrined due to erratic, opportunistic or unpredictable changes by regulators or policymakers, firms will act rationally in response (Kydland and Prescott, 1977; Rogoff, 1985; Taylor, 1985; Batabyal, 1996; Virag, 1999; Haubrich, 2000; Brito et al. 2011). Indeed, the literature highlights that only one erratic decision is required to create a dynamic inconsistency problem.

That investment may be delayed in the NEM is more than a theoretical possibility - evidence from the NEM largely follows the theory. Plant investment patterns in NSW demonstrate these concepts. During 2004-2007, regulated price caps were set at levels materially below the supply chain LRMC. Table 1 summarises 2004-2007 NSW market data, and the two adjacent interconnected regions of Queensland and Victoria. Note in Table 1 that NSW had the highest spot price (\$41.92/MWh), the highest aggregate market value (\$11.7 billion) and the highest present value of forward prices ${ }^{19}$ in the over-the-counter market $(\$ 36.36 / \mathrm{MWh}){ }^{20}$

Table 1: Base load prices - 2004-2007

\begin{tabular}{lrrrr}
\hline NEM & $\begin{array}{r}\text { 3Yr Forward } \\
\text { Region }\end{array}$ & $\begin{array}{r}\text { Actual Spot } 2 H 2003^{*} \\
\text { Prices 04-07 } \\
(\$ / M W h)\end{array}$ & $\begin{array}{r}\text { Aggregate } \\
\text { Generation } \\
(\mathrm{MWh})\end{array}$ & $\begin{array}{r}\text { Aggregate } \\
\text { Market Value } \\
(\$ \mathrm{Mm})\end{array}$ \\
\hline NSW & 36.36 & 41.92 & 278,573 & 11,676 \\
QLD & 34.30 & 34.35 & 176,005 & 6,046 \\
VIC & 33.08 & 35.07 & 176,183 & 6,178 \\
\hline Total/Avg & 34.58 & 37.89 & 630,761 & 23,900 \\
\hline
\end{tabular}

Source: AFMA, AEMO. * 3 year forward calander year base load contracts covering CY 05-CY07.

In 2003, the independent market operator highlighted a lack of generation reserves in NSW by 2006 (NEMMCo, 2003). On this basis, one might expect that a dominant proportion of the roughly 2,000MW of new plant added to the NEM's (then) 38,000 MW existing plant stock during 2004-2007 would be sited in NSW. However, esaa (2013) data reveals no plant was built in NSW. All capacity investments were directed to the adjacent interconnected regions of Queensland and Victoria. Writing PPAs in NSW was uneconomic. Since credit-rated retailers were unable to write PPAs in NSW without incurring economic losses, none were written. Following a shift in economic policy settings whereby NSW default tariff caps were reset at the total supply chain market cost based on LRMC principles, a surprisingly large $79 \%$ of the next 2,200MW of investments in new capacity (i.e. between 2008-2010) was sited in NSW (Simshauser and Laochumnanvanit, 2012). Had the 2004-2007 investment blackout continued through to 2010 after the change in regulatory strategy - it may indicate that some other factor was constraining generation plant developments. But there is little doubt that the change in policy and the force it was delivered by the NSW Government was met with success.

While energy-only markets were initially designed with stand-alone generators and retailers events in the capital markets and the harsh experience of bankruptcies and losses associated with merchant power plants in the USA, Australia and UK meant that the 'merchant model' was essentially broken by the mid-2000s (Joskow, 2006; Finon, 2008; Simshauser, 2010, Nelson and

\footnotetext{
${ }^{19}$ It is also worth noting that the 3-year forward curve for base load swaps throughout the period 2001-2004 was in contango in NSW, and in backwardation in QLD.

${ }^{20}$ Table 1 includes aggregate generation (GWh) and aggregate market value (\$ million) metrics to highlight the fact that the NSW region is a particularly 'large market' in relative terms. From a purely practical perspective, this tends to discount any notion that the post-entry environment might represent a barrier to scale-efficient new investment. By contrast, entering at 'the efficient scale' in a small market may lead to a highly unbalanced post-entry environment due to excess supply. In other words, all things being equal, one might expect spot and forward prices to rise to higher levels before entry occurs in a small market due to the higher entry costs associated with smaller, less efficient power plant.
} 
Simshauser, 2013). As Caplan (2012) infers, long dated contracts and industrial organisation have been essential remedies to Finon's (2008) market failure, and as a result stylising an efficient wholesale portfolio solely on the basis of 1-3 year hedge contracts collides with the academic literature and practical evidence on energy-only markets, and therefore, should be rejected as a concept in policy design.

\subsection{Asymmetric information, short run prices and unintended damage to competition}

One of the difficulties of setting regulated price caps using a short run pricing approach is the extent of assumptions required to produce an outcome. A prudent portfolio of hedge contracts must be selected and half-hourly forecast spot prices must be produced - which relies on proprietary electricity system models, colloquially known as 'black boxes' within the industry.

Principle \#2: In workably competitive energy-only markets, any regulated price cap should be set as a safety-net to avoid unintended damage to the levels of competition or economic losses arising from mis-specifying highly uncertain future clearing prices.

A regulator cannot be expected to predict the efficient price 18 months in advance when the evidence is that the whole of the market cannot. In the case of the Queensland determination, despite the best efforts of the regulator and their economic advisors, (ex-carbon) wholesale prices were calculated/predicted to be $\$ 42 / \mathrm{MWh}$ and less than three months into the determination period, evidence from the financial markets indicated that year-ahead forward contracts had jumped by \$8/MWh (19\%). Predicting the appropriate level of Bertrand competition amongst rival electricity entities at the retail level is subject to substantial risk of error given asymmetric information. As Yarrow (2008, p15, p21) explained:

...price regulation in competitive market situations generally harms economic efficiency... It can be said that regulators, no matter how wise and no matter how well resourced, could be expected to make significant mistakes - because the problem has to do with information. The determination of a competitive price is a process that makes use of huge amounts of information, of such scale and scope as cannot feasibly be processed by a single decision making unit such as a regulatory agency...

An insurmountable difficulty for regulatory authorities is therefore to define a single pointestimate of a prudent retailer's hedge book, and then to predict how that hedge book might be translated into dynamic retail products and competitive pricing. This is compounded by the fact that competitive energy retailers are no longer uniform in terms of financial structure, scale, scope, strategic intent and most other business variables. Where price regulation represents a policy constraint, reverting to a stylised hedge book based on short run pricing as the single point of reference will, by definition, damage any business that has a long-term planning bias. Conversely however, sole reliance on LRMC will eventually damage businesses that have a short-term planning bias, particularly during system stress conditions. As Yarrow (2008, p.30) observed:

If, in classic fashion, a price cap were set at a level close to average total cost including a normal return on capital, the effect would be that an efficient supplier would necessarily earn a less than normal rate of return, with damaging implications for investment and innovation. In terms of profits, the supplier would see an upside that was truncated by regulatory controls alongside a downside that was increasing as competitive constraints grew. To avoid any highly damaging incentive effects, any [safety net] price cap must be above the level at which it would be set for a monopoly with the same cost structure... 
The implications of Yarrow's (2008) observations are clear. In a competitive market with a regulated price cap policy constraint, $L R M C$, (or some margin above it) should form a lower bound as the safety net. Indeed, the NSW regulatory strategy from 2007 has been to examine short run prices and LRMC, and set the regulated (safety net) price cap at the higher of the two and the evidence is that it has accommodated the array of competitive business models with competition rising sharply thereafter as Table 2 later reveals. The presence of different business models sharpens competitive intensity and requisite capital flows - and thus results in more efficient products, pricing and investment. Specifically, some retailers have a short-run planning bias (i.e. high use of short term instruments) and are highly competitive in over-equipment scenarios. Other retailers have a distinct long-run planning bias (i.e. high use of PPAs and direct investments) and are highly competitive and 'market stabilising' in under-equipment scenarios. Bushnell, Mansur and Saravia (2007) found that integrated retailers have a moderating effect on price because forward commitments to customers are made ahead of time, thus reducing the incentive to raise wholesale price. Such an outcome is also consistent with the literature on $e x$ ante price discrimination and customer loyalty in oligopolistic settings (Armstrong, 2006). These are important findings and it is not in the long run interests of consumers or Australia's macro economy to have this level of competitive diversity truncated due to dynamic inconsistency via regulatory instrument.

So are retail electricity markets in Queensland, New South Wales, Victoria and South Australia competitive? There is no universal test that determines whether a market is competitive, although the AEMC (2008a, 2008b, 2013) has set out a framework to guide analyses undertaken on behalf of NEM jurisdictional governments. This includes a review of customer switching, the intensity of rivalry, the ease of entry and exit and so on. The AEMC reviews of Victoria, South Australia and New South Wales found them to be workably competitive. ${ }^{21}$ Victoria proceeded with removing regulated price caps in 2008 as did South Australia in 2013. As a result, the NEM has a rich history of deregulated and price cap regulated experience to examine. Table 2 provides a comparative analysis of NEM customer switching rates from 2004-2013.

Table 2: Residential customer switching rates 2004-2013

\begin{tabular}{|c|c|c|c|c|c|}
\hline Switch rate (Annual) & NSW & VIC & SA & QLD & NEM \\
\hline June 2004 & $5 \%$ & $12 \%$ & $11 \%$ & $\mathrm{n} / \mathrm{a}$ & $9 \%$ \\
\hline June 2005 & $6 \%$ & $20 \%$ & $17 \%$ & $\mathrm{n} / \mathrm{a}$ & $13 \%$ \\
\hline June 2006 & $9 \%$ & $21 \%$ & $19 \%$ & $\mathrm{n} / \mathrm{a}$ & $15 \%$ \\
\hline June 2007 & $12 \%$ & $26 \%$ & $11 \%$ & $\mathrm{n} / \mathrm{a}$ & $17 \%$ \\
\hline June 2008 & $10 \%$ & $23 \%$ & $17 \%$ & $16 \%$ & $16 \%$ \\
\hline June 2009 & $11 \%$ & $26 \%$ & $15 \%$ & $17 \%$ & $17 \%$ \\
\hline June 2010 & $13 \%$ & $27 \%$ & $14 \%$ & $18 \%$ & $18 \%$ \\
\hline June 2011 & $14 \%$ & $27 \%$ & $18 \%$ & $25 \%$ & $21 \%$ \\
\hline June 2012 & $17 \%$ & $26 \%$ & $22 \%$ & $21 \%$ & $21 \%$ \\
\hline June 2013 & $20 \%$ & $29 \%$ & $22 \%$ & $18 \%$ & $23 \%$ \\
\hline Total Customers & $3.4 \mathrm{~m}$ & $2.6 \mathrm{~m}$ & $0.8 \mathrm{~m}$ & $1.3 m^{*}$ & $8.1 \mathrm{~m}$ \\
\hline Total Switching^ & $60 \%$ & $80 \%$ & $83 \%$ & $73 \%$ & $71 \%$ \\
\hline
\end{tabular}

These data provide 36 region years of electricity industry competitive activity. To provide context around the notion of that competitive intensity, Table 3 provides static parallel industry

\footnotetext{
${ }^{21}$ Specifically, marketing rivalry was vigorous and conditions for entry and expansion were judged to be favourable, with incumbent retailers competing against 10 or more new entrants. New entrants had created a credible threat having steadily eroded a substantial component of incumbent market share. Typically more than $60 \%$ of customers had switched away from the 'default' regulated tariff. More than $80 \%$ of customers were aware of the ability to switch electricity retailer, and retailers were contacting customers directly with discounted offers and non-price benefits.
} 
benchmarks of customer switching. Note that the NEM has by far the highest customer switching rate of all industries presented.

Table 3: Customer switching rates in Australian Industries

\begin{tabular}{lr}
\hline Industry & Switching Rate \\
\hline NEM Electricity & $23 \%$ \\
NEM Gas & $18 \%$ \\
Broadband & $15 \%$ \\
Mobile Phones & $13 \%$ \\
Pay Television & $12 \%$ \\
Insurance & $12 \%$ \\
Airlines & $10 \%$ \\
Banking & $8 \%$ \\
Health & $4 \%$ \\
Superannuation & $4 \%$ \\
\hline
\end{tabular}

Source: AEMO, Tindal (2008); Roy Morgan Research; Buddle (2008); AMR Interactive; RFI; PHIAC; ASFA.

Table 2 reveals two important findings. First, in markets where the approach to price cap regulation was stable (and set at LRMC), and in the deregulated markets where standing tariffs reflect LRMC levels (i.e. Victoria and more recently, South Australia), competitive activity and switching rates have remained high. ${ }^{22}$ Second, in regions in which regulated price caps have been set below supply-chain LRMC (i.e. New South Wales 2004-2006, Queensland 2013) competition and switching rates lagged national averages materially. The Queensland 2012/2013 determination is worth examining in greater detail. Figure 2 presents data on industry marketing resources, routine product discounts, and the resulting change in customer Switching Velocity in the period before and after the announced change in methodology.

Figure 2: $\quad$ Marketing Resources, Switching Velocity and Routine Discounts in Queensland

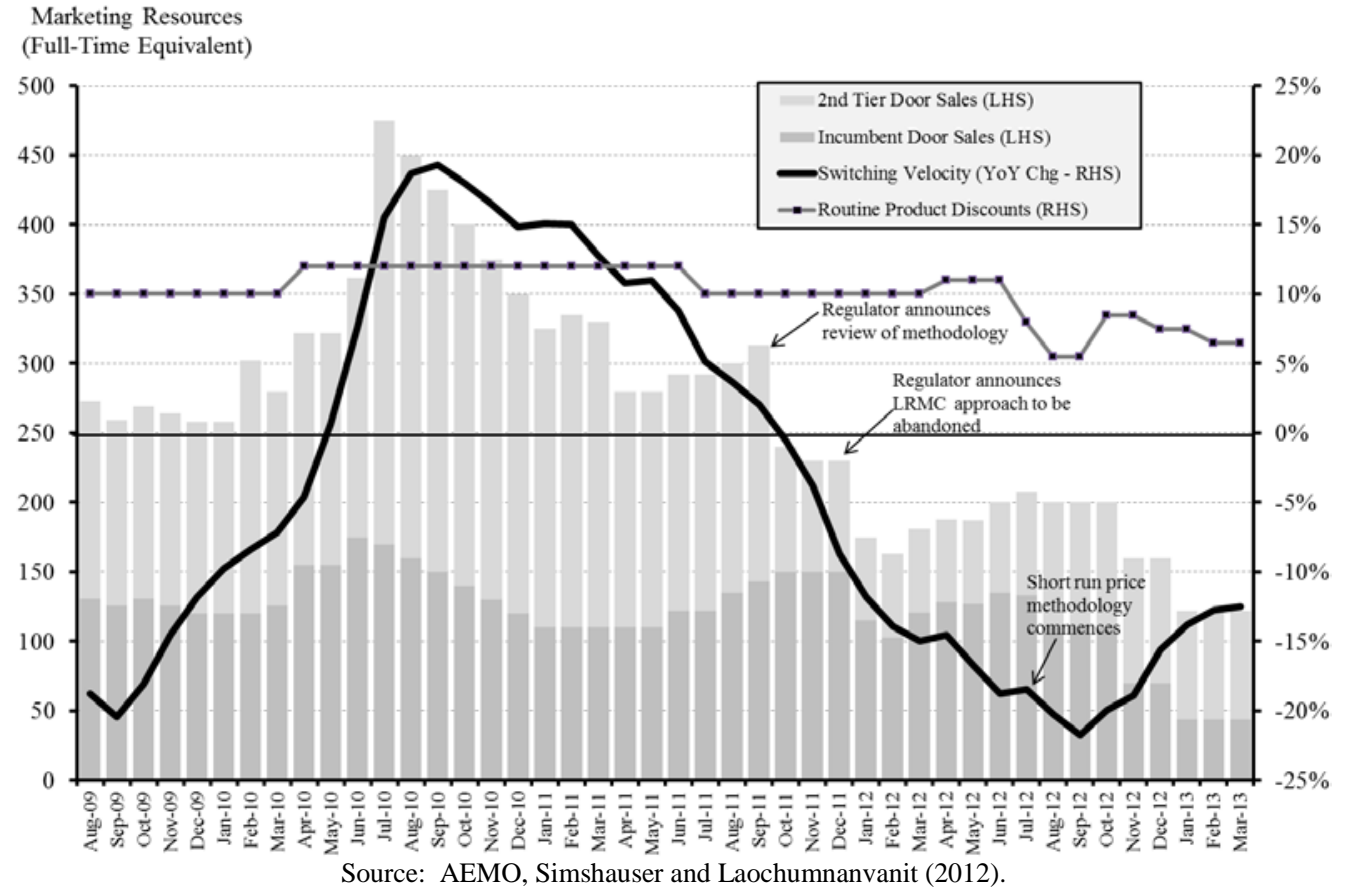

In Figure 2, the bar chart (LHS Axis) measures the allocation of marketing resources or door-todoor sales representatives - split between the incumbent and $2^{\text {nd }}$ Tier retailers. Notice the sharp

\footnotetext{
${ }^{22}$ In the case of Victoria it could be argued that the level of switching is at socially excessive levels.
} 
drop from late-2011 amongst retailers as the methodology review and change was announced. Next is the level of routine product discounts, which is measured by the grey line series on the RHS axis. Note that once the short run price methodology result is announced and implemented in mid-2012, price discounts drop and settle at 7\%. Finally, Switching Velocity (black line trace measured on the RHS Axis) largely follows the price and product marketing results. Switching Velocity is a measure of the Year-on-Year change in the total number of customers who have switched - and any result above the origin means that market competition is accelerating, and results below the origin mean that market competition is contracting at varying levels of intensity.

The extent of the regulatory-induced change in competition levels can also be captured by comparing Queensland's Customer Switching Rate (as distinct from Switching Velocity) to broader market movements, which is presented in Figure 3.

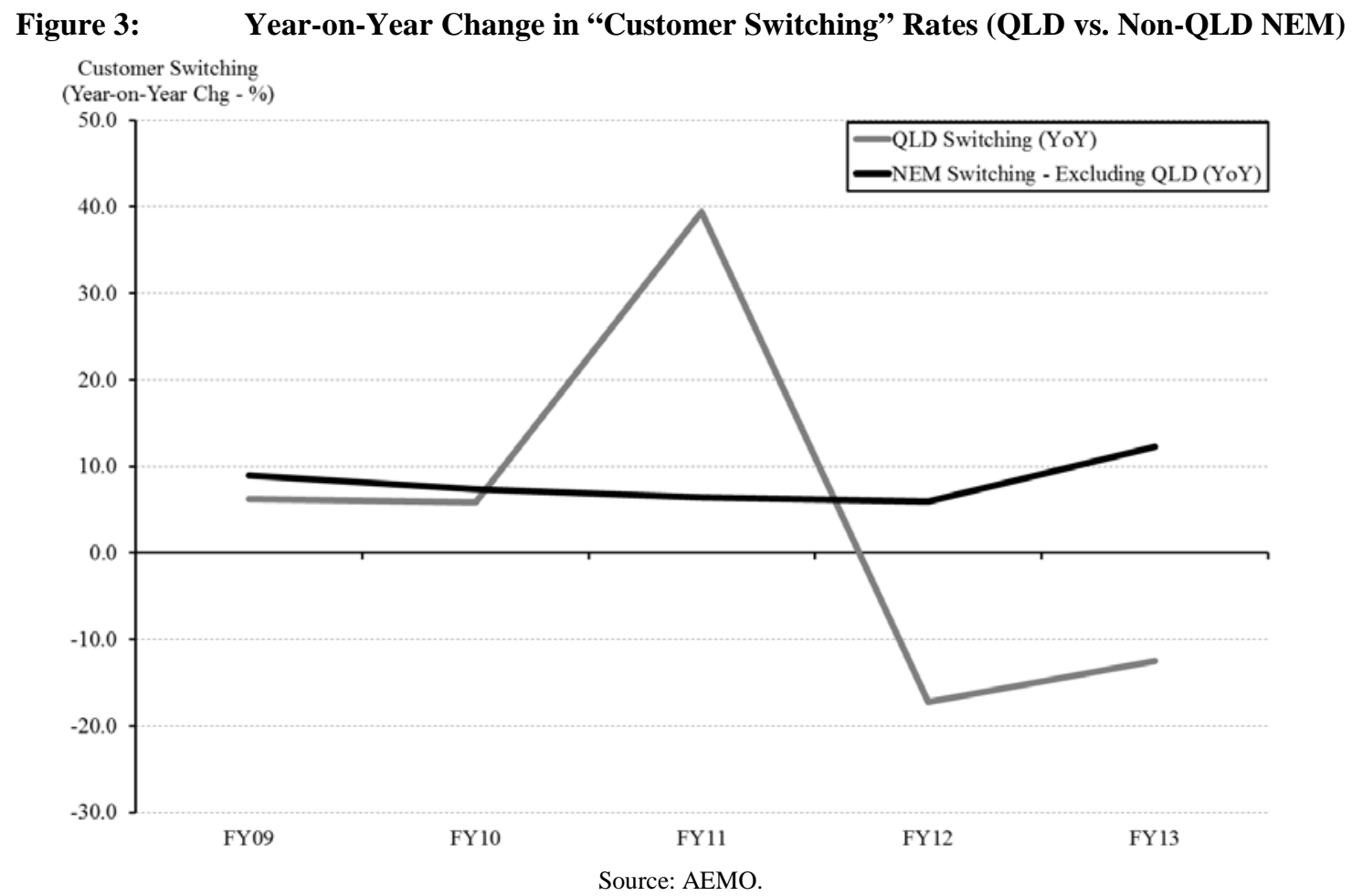

Queensland recorded two years of negative growth in customer switching rates of $-17.0 \%$ and $-12.5 \%$ respectively, while the balance of the market continued to record positive (Year-on-Year) customer switching rates of +6 and $+12 \%$ respectively as Figure 3 illustrates. The differential between these outcomes is material, and had Queensland followed broader market trends, switching results in FY12 and FY13 would have resembled those of Victoria - an 11 percentage point difference by FY13.

Evidence from the NEM is that each time regulated price caps have been set well below supplychain LRMC, during structural oversupply or otherwise, the intensity of competition has shown a marked departure from trend rates. And while it can be said that customer switching is not the only measure of competitive intensity, as one peer reviewer noted, it provides the only practical evidence of active consumer participation in response to competitive pressure.

\subsection{The role of non-linear pricing and the effects of truncating default tariffs}

VassaETT (2012) measures the competitive intensity of retail competition across more than 40 energy markets and consistently finds Victoria to be the most world's most competitive. Yet there are a non-trivial segment of customers in each region that remain on default tariffs. Recall 
from Figure 1 that under an LRMC approach, the Default Tariff in Queensland would be set at $\$ 25.6 \mathrm{c} / \mathrm{kWh}$ while routine discounts of $10-12 \%(23.1 \mathrm{c} / \mathrm{kWh})$ would be available - yet $27 \%$ of customers remain on default tariffs (although to be sure, non-price benefits such as Fly-Buys and Web Portals have not been accounted for). In the UK, Hviid and Waddam Price (2012, p237) observe that retailers in that market routinely offer $10 \%$ discounts yet almost half the customer base remains with their incumbent retailer, 'indicating substantial loyalty'. The relevant question in a workably competitive market is, do these 'sticky customers' represent a problem for policymakers that warrants intervention?

Principle \#3: In workably competitive energy-only markets, attempting to regulate nonlinear pricing out of existence will not enhance welfare - it will result in rising marginal prices and disrupt the role of prices in efficient fixed and sunk cost recovery through dynamic inconsistency.

A branch of the literature on energy-only markets finds that far from being a problem, the combination of sticky customers (or even a franchise of customers) and non-linear pricing plays a crucial role solving for Resource Adequacy (Newbery, 2001; Green, 2004; Joskow, 2006; Michaels 2006; Chao et al., 2008; Finon, 2008; Simshauser, 2010). Ng (1987) shows that in publicly owned industries such as water, linear pricing at short run marginal cost need not lead to cumulative deficits, as is commonly feared. However, he also observes that the required fluctuations in short run prices may be unusually large making them politically infeasible. More importantly however, $\mathrm{Ng}$ (1987, p.22) notes that "the so-called short-run can be very long [and] if short run marginal cost pricing is below long run average cost, short run marginal cost pricing results in perennial losses." 23 As a result, and as is well understood in the academic literature on substantial fixed and sunk cost industries and energy-only markets in particular, uniform pricing at (short run) marginal cost is not economically viable given scheduled debt financing commitments (Nelson and Simshauser, 2013). Simshauser and Ariyaratnam (2014) provide a mathematical proof for this proposition in relation to energy-only markets, while Bidwell and Henney (2003) and Simshauser (2008) demonstrate these principles via static and dynamic power system modelling, respectively.

Above all, the presence of differential or non-linear pricing, in which some sub-set of products are priced above marginal cost, does not mean that conditions for (Pareto) efficiency have not been met in industries characterised by substantial fixed and sunk costs. For a market to meet the definition of (Pareto) efficiency, a necessary condition is that the marginal willingness to pay must equal marginal cost. As Varian (1996, p1) explains:

...forcing firms to charge a price equal to marginal cost can easily fail to be efficient if such pricing fails to cover total costs... marginal willingness to pay refers to the willingness to pay for an incremental unit of the good and marginal cost refers to the cost of providing an incremental unit of the good. Once these terms are understood, it is not hard to see why efficiency requires that marginal willingness to pay must equal marginal cost... If consumers pay a constant price for each unit of the good they consume, then it follows that the price must be equal to marginal cost. On the other hand, there is nothing inherent in these principles that says the price must be constant - non-linear prices are very common in the real world. [For industries with substantial fixed and sunk costs] efficient pricing only requires that the marginal unit of the good must be sold at marginal cost - not that every unit of the good must be sold at marginal cost...

\footnotetext{
${ }^{23} \mathrm{Ng}$ (1987) discusses this in considerable detail in the context of a publicly owned water utility. Such an institution may well be able to tolerate prolonged periods of below long run marginal cost pricing, and subsequent periods of above average cost pricing such that overall, a surplus is produced. However, as Nelson and Simshauser (2013) and Simshauser and Ariyaratnam (2014) demonstrate, privately owned generation plant that are financed with the typical mix of debt and equity are simply unable to navigate such prolonged conditions of short run marginal cost pricing without experiencing financial distress. 
Varian (1996) demonstrates in industries where uniform pricing at marginal cost is not economically viable, non-linear pricing is the most efficient manner for a firm to recover substantial fixed and sunk costs and under certain conditions is welfare enhancing. Accordingly, an attempt to regulate non-linear pricing out of existence in energy-only markets through the application of short run wholesale pricing in regulated price caps can therefore harm economic efficiency and consumer welfare in the short and long run.

Existing literature on price discrimination is well summarised by Armstrong (2008). While the literature on price discrimination finds its roots in monopoly applications, a special strand emerged which analyses the role of price discrimination in competitive industries. One of the original contributions came from Salop and Stiglitz (1977) which focused on informed (weak segment) and uninformed (strong segment) customers and was later extended by Katz (1984) although the use of completely inelastic demand functions limits welfare enhancements. The literature on non-linear pricing in symmetric markets (where firms agree on strong and weak customer segments) finds that reverting to uniform prices will reduce default prices but raise marginal prices, thus landing inbetween (Borenstein, 1985; Holmes 1989; Winter, 1997; Dobson and Waterson, 2006). In the event, the net effect on consumers is ambiguous.

However, the literature relevant to the special case of electricity markets can be traced back to Corts (1998). He shows that in asymmetric markets, where firms do not agree on which customer segments are 'strong' and 'weak', truncating non-linear pricing is likely to lead to an overall increase in prices and damage consumers. Bester and Petrakis (1996) find banning discrimination raises marginal prices and as with Shaffer and Zhang (2000), conclude that this always damages some consumer groups. Shaffer and Zhang (2000) also derive conditions by which all consumers can be damaged. Crucially, Hviid and Waddam Price (2012) examined limits placed on nonlinear pricing by the regulator in the British energy market and found the response by firms to non-discrimination rules generated detrimental distributional effects and had a range of unintended adverse consequences. Specifically, they found that because the market was asymmetric with regards to which customers were strong and weak, the result was to raise all prices as the literature predicts. The regulator found in a post-implementation review that many indicators of competition had deteriorated and in the event, abandoned the policy. As Hviid and Waddam Price (2012, p.249) concluded:

Standard economic models... provide recommendations which seem diametrically opposed to the preferences exhibited by many politicians and consumer groups...

Considered from an applied perspective, customers may find themselves on default tariffs because their market contract has matured and they have failed to act on termination. Other customers remain on default tariffs because there are real transaction costs involved in switching, and the cost and inconvenience of searching outweighs expected benefits. Other households may choose to avoid fixed-term market contract due to an imminent move-out. AGL Energy has about a 25\% market share and experiences at least 250,000 customer relocations annually. Accordingly, some proportion of the roughly 1 million customer movers will re-establish (at least initially) on a default tariff before switching. Regardless, a household's utility function may well be maximised despite being on a default tariff due to the existence of search and transactions costs, non-price benefits and other factors. The purpose of energy market reform is to facilitate customer choice, not second-guess customer choice. Although, for 'sticky customers' who are on low incomes, disabled, or have low levels of literacy and numeracy or command of the English language, clearly, the issue is vexed and highly targeted policies may be appropriate.

For all other customers, to the extent that policymakers are concerned by the presence of sticky customers, what can be done if truncating regulated price caps damages consumer welfare, and runs a heightened risk of inducing dynamic inconsistency? The better view is to focus on 
switching campaigns, as the New Zealand Government has successfully done. ${ }^{24}$ The evidence presented in Nelson and Reid (2014) tends to confirm that more can be done to better inform customers about market contracts.

Nonetheless, if price cap regulation is a policy constraint due to political processes, then the objective function should be to form a safety-net tariff, set at LRMC or some margin above it as Yarrow (2008) explains. Price regulation in workably competitive markets pursues a very different objective function when it attempts to deliver the expected benefits of competition to customers who chose not to avail themselves of discounted market offers. At this point, the purpose of a regulated tariff cap starts simulating what competitive markets are predicted to deliver using entirely inadequate information.

\section{Policy Implications and Concluding Remarks}

The case for price regulation with respect to electricity networks is clear in that these natural monopoly businesses, left to their own devices, may exercise market power and raise prices above efficient levels and extract sustained economic rents. Consumers will pay more for electricity than they should and the resulting allocation of resources throughout the economy would be less than optimal. Price regulation under such conditions is appropriate and is designed to drive efficiency, and, determine how subsequent gains are shared between networks and consumers.

The circumstance in which price regulation has role to play in a competitive market setting is in the early stages of a reform, that is, to ensure a smooth transition for all participants from monopoly to a 'workably competitive' environment. In newly reformed markets, price regulation is not intended to second-guess the competitive price but to provide a safety-net from the potential abuse of market power by a dominant participant during the transition to a competitive environment (noting that the dominant player is frequently the former monopoly supplier).

Price regulation ceases to have an economic function once a market exhibits workably competitive characteristics. It is in the interests of promoting economic efficiency and the greatest consumer benefit to allow market forces to determine the appropriate level at which prices are set when competition is effective. If a subsidiary objective of price cap regulation within a competitive market is to reduce the incidence of vulnerable households, it will fail. It will not achieve outcomes consistent with reducing hardship. A price that is low enough to reduce energy customer hardship will damage competition, innovation and the flow of capital, none of which is in the long term interests of all consumers. ${ }^{25}$

To the extent that regulated price caps form a policy constraint due to political processes, clearing prices in workably competitive retail markets should be set by the hands of market forces, not predicted and then capped at that level by a regulator. There is no stated objective function for retaining regulated price caps in workably competitive retail markets in Australia. We must postulate why they remain - and the most likely basis is lingering concerns over potential abuse of market power by incumbent retailers, in spite of the findings of the AEMC and the evidence in Section 4.2. Yet, without a clearly articulated objective function, regulators interpret a mandate without guidance, and the evidence tends to suggest that this is has not always resulted in satisfactory outcomes.

So when does electricity price cap regulation become distortionary? The literature and evidence presented in this article tends to indicate that when a price cap attempts to define the competitive

\footnotetext{
${ }^{24}$ In New Zealand, switching has now increased to $22 \%$ up from $14 \%$ only two years ago, largely driven by a government campaign focused on "switch and save" (VassaETT, 2012).

${ }^{25}$ Energy customer hardship requires quite specific policies such as concessions or rebates, and ideally, funded via progressive sources of taxation. See for example Simshauser and Nelson (2014).
} 
price in workably competitive markets, it has a propensity to result in distortions and unintended consequences due to asymmetric information. There are risks of producing erroneous estimates, of dynamic inconsistency when methodological changes collide with the way in which the industry solves for efficient capital flows, and the risk of distorting the role that non-linear pricing plays in both fixed cost recovery and in maximising consumer utility functions and welfare. To the extent that a State Government enforces regulated price caps, three guiding principles should ideally be adopted when the energy-only market is workably competitive:

1. Some minimum level of vertical integration of merchant businesses is required for ongoing physical and systemic power system stability due to capital market constraints;

2. Regulated price caps should be set as a safety-net to avoid unintended damage to the levels of competition or economic losses arising from mis-specifying highly uncertain competitive market prices; and

3. Attempting to regulate against non-linear pricing will not enhance welfare - it will result in rising marginal prices and disrupt the role of pricing in fixed and sunk cost recovery through dynamic inconsistency.

It would seem that the NSW policy of setting the wholesale cost component of the default tariff at LRMC (with short run wholesale prices as a cap) is closely aligned to these three guiding principles. The evidence also tends to indicate that this methodology has been durable for the period 2007-2016f, even in the presence of constrained supply (initially), followed by the introduction of carbon pricing, then subsequent oversupply, a privatisation program and in the near future, the expected removal of carbon pricing - with very little changes to the way the policy is implemented or operates. ${ }^{26}$ The concept of 'headroom' does appear to be important, as Yarrow (2008) explains. Applied analysis undertaken by NSW regulator IPART (2013) provides useful guidance - they revealed that when 'headroom' or available discounts fall below $10 \%$, activity in the competitive market begins to stall or contract. This is no doubt due to the heightened risk of financial failure - bearing in mind two second tier retailers have collapsed in the NEM due to exposures in price cap regulated regions.

As Yarrow (2008) notes, no matter how wise, asymmetric information will virtually ensure that the answer for determining the competitive price, set 18 months in advance, will be correct only by chance. Sophisticated trading floors of energy businesses, with significant resources, make "wrong calls" regularly in real-time. It is inconceivable that a regulator could project the competitive market price accurately 18 months ahead of time.

A framework that enables an independent regulator to squeeze a regulated price cap during a State political election (where prices freezes formed an election promise) will almost certainly result in a dynamic inconsistency problem. Capital markets confidence will rightly be tested, and there is little to suspect that under similar circumstances, another change to methodology would not be initiated if it suits political outcomes without clear policy guidance. It almost goes without saying that few outcomes in capital-intensive industries could be more long-run damaging than dynamic inconsistency.

\section{References}

AEMC: Australian Energy Market Commission, 2008a, Review of the Effectiveness of Competition in Electricity and Gas Retail Markets in Victoria, Second Final Report, 29 February 2008, Sydney.

\footnotetext{
${ }^{26}$ There was a change to the methodology in which the LRMC component was shifted to $75 \%$ and short run prices formed the remaining 25\%. However, a parallel adjustment to the retail costs and margins was instituted simultaneously and so the outcome remained largely consistent.
} 
AEMC: Australian Energy Market Commission, 2008b, Review of the Effectiveness of Competition in Electricity and Gas Retail Markets in South Australia, Second Final Report, 18 December 2008, Sydney.

AEMC: Australian Energy Market Commission, 2013, Review of the Effectiveness of Competition in Retail Electricity and Natural Gas Markets in New South Wales, Draft Report, 23 May 2013, Sydney.

Armstrong, M., 2006, "Recent Developments in the economics of price discrimination”, in R.Blundell, W. Newey, and T. Persson, (ed.), Advances in Economics and Econometrics: Theory and Applications: Ninth World Congress of the Econometrics: Theory and Applications. Ninth World Congress of the Econometric Society, Cambridge University Press, Cambridge.

Armstrong, M., 2008, “Price Discrimination”, in P. Buccirossi (ed.) Handbook of Antitrust Economics, The MIT Press, Cambridge, MA.

ASFA: The Association of Superannuation Funds of Australia Limited, 2009, "ASFA Submission to the Cooper Super System Review: Phase Two: Operation and Efficiency - Appendix 1”. ASFA Publication. Available at http://www.superannuation.asn.au/submissions/default.aspx

Batabyal, A. (1996), "Consistency and Optimality in a dynamic game of pollution control II: monopoly”, Environmental and Resource Economics, Vol.8, pp 315-330.

Banks, G. (2012), "Productivity policies: the "to do" list”, Economic and Social Outlook Conference, Melbourne 1 November 2012.

Bain, J. 1956, Barriers to new competition - their character and consequences in manufacturing industries, Harvard University Press, Cambridge.

Bester, H. and Petrakis, E. (1996), “Coupons and oligopolistic price discrimination”, International Journal of Industrial Organisation, 14: 227-242.

Bidwell, M. and Henney, A. (2004), “Will Neta ensure generation adequacy?”, Power UK, 122:10-26.

Borenstein, S. (1985), “Price discrimination in free entry markets”, RAND Journal of Eocnomics, 16: 380397.

Brito, D., Pereira, P. and Vareda, J. (2011), “Investment, dynamic consistency and the sectoral regulator's objective”, $8^{\text {th }}$ Asia-Pacific Regional ITS Conference, Taipei 2011. Available at http://econstor.eu/bitstream/10419/52341/1/673079651.pdf. Accessed July 2013.

Buddle, P. 2008, “Australia - Industry - Churn”, Buddle Communication Publication, available at http://www.budde.com.au/Research/Australia-Industry-Churn.html

Caplan, E. (2012), "What drives new generation construction? An analysis of the financial arrangements behind new electric generation projects in 2011”, The Electricity Journal, 25(6): 48-61.

Chao, H., Oren, S. and Wilson, P. (2008), "Reevaluation of vertical integration and unbundling in restructured electricity markets”, in Sioshansi, F.P. (ed.), Competitive Electricity Markets: Design, Implementation and Performance. Elsevier, London, pp. 27-65.

Corts, K. (1998), "Third-degree price discrimination in oligopoly: all-out competition and strategic commitment”, RAND Journal of Economics, 29(2): 306-323.

Dobson, P. and Waterson, M, (2006), “Chain-store competition: customized vs. uniform pricing” Warwick Economic Research Papers, No.840.

ERIG: Energy Reform Implementation Group, 2006, “Impediments to investment in Australia’s energy markets”, ERIG Publication, Canberra. 
Finon, D. 2008, “Investment risk allocation in decentralised markets: the need of long-term contracts and vertical integration”, OPEC Energy Review, 32(2): 150-183.

Green, R. (2004), “Retail competition and electricity contracts”, CMI Working Paper 33, Cambridge.

Haubrich, J. (2000), “Waiting for policy rules”, Economic Commentary, Federal Reserve Bank of Cleveland, January 2000, pp1-5. Available at

http://www.clevelandfed.org/research/Commentary/2000/0115.htm

Holmes, T. (1989), “The effects of third degree price discrimination in oligopoly”, American Economic Review, 79: 244-250.

IPART, 2013, "Review of retail electricity prices and charges for electricity”, IPART Publication, Final Report June 2013, Sydney. Available at http://www.ipart.nsw.gov.au

Joskow, P. 2006, “Competitive electricity markets and investment in new generating capacity”, Center for Energy and Environmental Policy Research Working Paper 06-009. Published in Helm, D. (ed.) The New Energy Paradigm, Owford University Press, Oxford, 2007.

Kydland, F. and Prescott, E. (1977), "Rules rather than discretion: the inconsistency of optimal plans", The Journal of Political Economy, 85(3): 473-492.

Lintner, J. (1965), “The valuation of risk assets and the selection of risky investment in stock portfolios and capital budgets”, Review of Economics and Statistics, 47(Feb): 13-37.

Michaels, R. (2006), “Vertical Integration and the restructuring electricity markets”, Policy Analysis, 572: $1-31$.

Modigliani, F. 1958, “New developments on the oligopoly front”, Journal of Political Economy, 66(1): 215-232.

Nelson, J. and Simshauser, P. 2013, “Is the Merchant Power Producer a Broken Model?”, Energy Policy, Vol.33, pp 298-310.

Nelson, T. and Reid, C. 2014, “Reconciling energy prices and social policy”, The Electricity Journal, Vol.27: article in-press.

Newbery, D. (2001), “Issues and options for restructuring the electricity supply industry”, Working Paper, Cambridge University, Department of Applied Economics.

Newbery, D. (2006), “Market Design”, EPRG Working Paper No. 0515, University of Cambridge. Available at http://www.eprg.group.cam.ac.uk/category/publications/working-paper-series

Ng, K. (1987), "Equity, efficiency and financial viability: public-utility pricing with special reference to water supply”, Australian Economic Review, 20(3): 21-35.

Productivity Commission, (2013), “Electricity Network Regulatory Frameworks”, Productivity Commission Inquiry Report Volume 1, No.62, Melbourne.

QCA: Queensland Competition Authority, (2012), “Regulated Retail Electricity Prices 2012/13”, QCA Publication, Brisbane. Available at www.qca.org.au

Roam: Roam Consulting, (2010), "Reliability standard and setting reviews”, Roam Consulting Publication, Brisbane. Available at http://www.aemc.gov.au/market-reviews/completed/review-of-the-reliabilitystandard-and-settings.html

Rogoff, (1985), “The optimal degree of commitment to an intermediate monetary target”, The Quarterly Journal of Economics, 100(4): 1169-1189. 
Shaffer, G and Zhang, Z. (2000), "Pay to switch or pay to stay: preference-based price discrimination in markets with switching costs”, Journal of Economics \& Management Strategy, 9:397-424.

Sharpe, W. (1964), “Capital Asset Prices: a theory of market equilibrium under conditions of risk”, Journal of Finance, 19(Sept): 425-442.

Simshauser, P. 2001, “Excess entry in the Queensland power market”, Economic Analysis and Policy, 31(1): 73-92.

Simshauser, P. 2006, “The emergence of structural faults on the supply-side in deregulated energy-only electricity markets”, Australian Economic Review, 39(2): 130-146.

Simshauser, P. 2008, "The dynamic efficiency gains from introducing capacity payments in the national electricity market”, Australian Economic Review, 41(4): 349-370.

Simshauser, P. 2010, "Vertical integration, credit ratings and retail price settings in energy only markets: navigating the Resource Adequacy problem”, Energy Policy, 38(11): 7427-7441.

Simshauser, P. and Ariyaratnam, J. (2014), “What is normal profit for power generation?”, Journal of Financial Economic Policy, Vol. 6: article in-press.

Simshauser, P. and Laochumnanvanit, K. 2012, "The political economy of regulating retail electricity price caps in a rising cost environment”, The Electricity Journal, 25(9): 48-66.

Simshauser, P. and Nelson, T, 2014, "The consequences of retail electricity price rises - rethinking customer hardship”, Australian Economic Review, article in-press.

Taylor, H. (1985), “Time inconsistency: a potential problem for policymakers”, Business Review - Federal Reserve Bank of Philadelphia, Mar-Apr 1985, pp. 3-12

Tindal, S. 2008, "Young churners the scourge of Aussie telcos", ZDNet Publication, available at http://www.zdnet.com.au/young-churners-the-scourge-of-aussie-telcos-339288193.htm

VaasaETT, 2012, “World Energy Market Rankings”, VaasaETT publication, available at www.vaasaett.com

Varian, H. (1996), “Differential pricing and efficiency”, First Monday, 1(2): 1-10. Available at http://dx.doi.org/10.5210\%2Ffm.v1i2.473

Yarrow, G. 2008, “Report on the Impact of Maintaining Price Regulation”, Regulatory Policy Institute, Oxford, United Kingdom.

Virag, G. (1999), Independence of a Regulatory Institution . A Means to Alleviate Credibility Problems in the CEE Countries, Case CEU Working Paper Series, Center for Social and Economic research, Central European University, Warsaw. Available at http://www.nbportal.pl/library/pub_auto_B_0001/KAT_B2170.PDF 